Check for updates

Cite this: New J. Chem., 2019, 43, 11334

Received 21st May 2019

Accepted 25th June 2019

DOI: 10.1039/c9nj02595b

rsc.li/njc

\title{
Investigating the effect of ligand and cation on the properties of metal fluorinated acetylacetonate based magnetic ionic liquids $\dagger$
}

\author{
Muhammad Qamar Farooq, ${ }^{a}$ Deepak Chand, ${ }^{a}$ Gabriel A. Odugbesi, ${ }^{a}$ \\ Marcelino Varona, ${ }^{a}$ Yaroslav Mudryk (DD ${ }^{b}$ and Jared L. Anderson (D) *a
}

\begin{abstract}
Magnetic ionic liquids (MILs) are a subclass of ionic liquids that possess a paramagnetic metal within their chemical structure, making them susceptible to external magnetic fields. A total of twenty-four (24) MILs were prepared and characterized to investigate the effect of the ligand, cation and anion on the physiochemical properties of acetylacetonate-based MILs. It was found that thermal stabilities as high as $260{ }^{\circ} \mathrm{C}$ could be achieved by incorporating aromatic moieties in the anion structure. Additionally, the magnetic moment could be modulated by simply changing the transition metal in the anion. Magnetic moment values of $2.8 \mu_{\mathrm{B}}, 4.5 \mu_{\mathrm{B}}$ and $5.6 \mu_{\mathrm{B}}$ were obtained by using $\mathrm{Ni}\left({ }^{\prime}\right), \mathrm{Co}(\|)$, and $\mathrm{Mn}(\|)$ as the metal centers, respectively. Furthermore, the viscosity of the MILs could be tailored from a few hundred centipoise to several thousand centipoise, increasing their potential applications in numerous interdisciplinary fields. Moreover, the MILs synthesized in this study were found to be insoluble in water at a MIL-to-solvent ratio of $0.01 \%(w / v)$, making them potentially useful in targeted separations, where very hydrophobic solvents are highly desired.
\end{abstract}

\section{Introduction}

Ionic liquids (ILs) are an intriguing class of non-molecular solvents comprised of organic cations and organic/inorganic anions. ${ }^{1,2}$ These molten organic salts possess low melting points $\left(\leq 100{ }^{\circ} \mathrm{C}\right)$ and an array of physiochemical properties including variable viscosity, low vapor pressure at ambient temperature, and high thermal stability. Moreover, the properties of ILs can be modified through careful selection of the cation/anion combination. ${ }^{3}$ This feature of structural tunability makes ILs attractive materials for a wide range of applications in various fields of science and engineering. A subclass of ILs that contain a paramagnetic component in the cation or anion structure are magnetic ionic liquids (MILs). ${ }^{4-8}$ These compounds possess many similar properties to traditional ILs, with the additional characteristic of responding to an external magnetic field. MILs have been successfully employed for density measurements via magnetic levitation, ${ }^{9}$ catalysis, ${ }^{10,11}$ magnetic fluids, ${ }^{12}$ cellulose dissolution, ${ }^{13}$ solvents in various organic reactions, ${ }^{14,15}$ electrochromic applications, ${ }^{16}$ and extraction of hazardous chemicals. ${ }^{17}$

The physicochemical properties of MILs can be tailored for specific applications through careful modification of the cation

\footnotetext{
${ }^{a}$ Department of Chemistry, Iowa State University, 1605 Gilman Hall, Ames,

Iowa 50011, USA. E-mail: andersoj@iastate.edu; Tel: +1 515-294-8356

${ }^{b}$ Division of Materials Science and Engineering, Ames Laboratory,

Iowa State University, Ames, Iowa 50011, USA

$\dagger$ Electronic supplementary information (ESI) available. See DOI: 10.1039/c9nj02595b
}

and anion structures. Among their interesting properties, magnetic susceptibility of MILs is often exploited in liquid-liquid extractions $^{17-19}$ and magnet-based sensors. ${ }^{20}$ The earliest reported MILs utilized simple halide-based, transition metal anions with the 1-butyl-3-methylimidazolium tetrachloroferrate(III) ([BMIM $\left.{ }^{+}\right]$$\left.\left[\mathrm{FeCl}_{4}{ }^{-}\right]\right)$MIL exhibiting an effective magnetic moment $\left(p_{\text {eff }}\right)$ of 5.8 Bohr magnetons $\left(\mu_{\mathrm{B}}\right)^{5,12}$ In order to significantly increase their magnetic susceptibility, trivalent lanthanide paramagnetic metals have been explored. Incorporation of Gd(III), Dy(III), and Ho(III) into the MIL chemical structure acts to increase their magnetic susceptibility due to higher paramagnetic moments compared to $3 \mathrm{~d}$ transition metals. ${ }^{9}$ Another strategy used to enhance magnetic susceptibility includes the incorporation of di- and tri-cationic structures containing multiple paramagnetic anions. ${ }^{21}$ Magnetic susceptibilities as high as $11.6 \mu_{\mathrm{B}}$ have been reported using a tricationic MIL framework. ${ }^{22}$

MILs have also drawn attention due to their low volatility, making them environmentally-friendly and suitable for high temperature applications such as solvents for organic synthesis, ${ }^{14,15}$ and gas-liquid chromatography. ${ }^{23,24}$ It has been observed that both the cation and anion components have a significant contribution towards the thermal stability of MILs. For example, Nacham et al. found that ammonium-based MILs had significantly lower thermal stability than dicationic imidazolium-based MILs. ${ }^{22}$ Another study investigated the effect of different cation and anion combinations on the thermal stability of MILs. By carefully manipulating the cation and anion and their combination, 
a tris(1-butyl-2,3-dimethylimidazolium)dysprosiumhexachlorate $\left(\left[\mathrm{BDMIM}^{+}\right]_{3}\left[\mathrm{DyCl}_{6}{ }^{3-}\right]\right) \mathrm{MIL}$ with relatively higher thermal stability $\left(334{ }^{\circ} \mathrm{C}\right)$ than previously reported MILs was prepared. ${ }^{9}$ Several studies have also demonstrated the effects of different MIL components, such as the composition of the cation and anion structures, ${ }^{25,26}$ metal center, ${ }^{27}$ and the alkyl chain length of imidazolium cations on the resulting viscosity. ${ }^{28}$ Lower viscosity MILs tend to be easier to handle and manipulate within fluid handling devices. Higher viscosity MILs have advantages in applications that require highly mechanically stable liquids. ${ }^{29}$ Yoshida et al. found that longer alkyl chain substituents in imidazolium-based MILs resulted in higher viscosity. ${ }^{28}$ Other approaches for modulating the viscosity include mixing two components of different viscosity to generate mixtures that contain lower viscosity than the individual components themselves. ${ }^{21}$

Recently, our group reported the preparation of a series of MILs consisting of hexafluoroacetylacetone (hfacac) ligands coordinated to different metal centers and paired with a phosphonium cation. ${ }^{30}$ These MILs exhibited very low viscosity, largely due to the bulky, asymmetric phosphonium cation, as well as very high hydrophobicity. ${ }^{31,32}$ However, it was observed that the thermal stability of these MILs appeared to be limited by the anion complex. Thermal stabilities as low as $130{ }^{\circ} \mathrm{C}$ were observed for the trihexyl(tetradecyl)phosphonium tris(hexafluoroacetylaceto)cobaltate(II) $\left(\left[\mathrm{P}_{66614}{ }^{+}\right]\left[\mathrm{Co}(\text { hfacac })_{3}{ }^{-}\right]\right) \mathrm{MIL}^{30}$ Therefore, in order to increase the broad applicability of these solvents, a systematic study that relates their chemical structure to observed physicochemical properties is required.

In this study, a total of twenty-four (24) MILs containing acetylacetone-based ligands were synthesized and characterized in an effort to better understand the relationship between ligand structure, cation type, and metal center on the resulting physicochemical properties. The effects of MIL cation/anion combination on thermal stability, hydrophobicity, magnetic susceptibility, and viscosity are thoroughly investigated. A series of different acetylacetone-based ligands with various transition metals centers (i.e., $\mathrm{Ni}(\mathrm{II}), \mathrm{Co}(\mathrm{II})$, and $\mathrm{Mn}$ (II)) were synthesized and paired with trihexyl(tetradecyl)phosphonium $\left(\left[\mathrm{P}_{66614}{ }^{+}\right]\right)$and 1-tetradecyl-3methylimidazolium $\left(\left[\mathrm{C}_{14} \mathrm{MIM}^{+}\right]\right)$cations. Through incorporation of aromatic moieties in the acetylacetone-based ligands, the thermal stability of the resulting MILs was increased up to $260{ }^{\circ} \mathrm{C}$, representing a significantly higher thermal stability than previously reported hfacac-based transition metal MILs $\left(130{ }^{\circ} \mathrm{C}\right.$, $155{ }^{\circ} \mathrm{C}$, and $215{ }^{\circ} \mathrm{C}$ for the $\mathrm{Co}(\mathrm{II}), \mathrm{Mn}$ (II), and Ni(II) transition metals, respectively). ${ }^{30}$ Moreover, it was found that the viscosity could be precisely tailored to range as low as 100 centipoise (cP) up to several thousand $\mathrm{cP}$. This study provides a fundamental understanding into the relationship between structure and physiochemical properties of acetylacetonate-based MILs.

\section{Experimental}

\subsection{Materials}

Ammonium hydroxide (28-30\% solution in water), 1,1,1,5,5,5hexafluoroacetylacetone (99\%) and nickel(II) chloride (98\%) were purchased from Acros Organics (Morris Plains, NJ, USA). Manganese(II) chloride tetrahydrate (98-100\%), 4,4,4-trifluoro1-(2-naphthyl)-1,3-butanedione ( $\mathrm{N}_{\mathrm{p}}$ tfacac, 98\%), 4,4,4-trifluoro1-phenyl-1,3-butanedione ( $\mathrm{P}_{\mathrm{h}}$ tfacac, 98\%) and 1,1,1-trifluoro2,4-pentanedione (tfacac, 98\%) were purchased from Alfa Aesar (Ward Hill, MA, USA). 4,4,4-Trifluoro-1-(2-thienyl)-1,3-butanedione ( $\left.\mathrm{T}_{\mathrm{h}} \mathrm{tfacac}, 98 \%\right)$ was purchased from Tokyo Chemical Industry (Portland, OR, USA). Cobalt(II) chloride (97\%), hexane $(98.5 \%)$, methanol (99.9\%), pyridine (>99\%), 1-methylimidazole (99\%) and acetonitrile (99.9\%) were purchased from MilliporeSigma (St. Louis, MO, USA). 1-Tetradecanol (97\%) and benzenesulfonyl chloride (98\%) were purchased from Beantown Chemical (Hudson, $\mathrm{NH}$, USA). Deuterated dimethyl sulfoxide $\left(d_{6}\right.$-DMSO) was obtained from Cambridge Isotope Laboratories (Andover, MA, USA). $\left[\mathrm{P}_{66614}{ }^{+}\right]\left[\mathrm{Cl}^{-}\right]$ (>93\%) was purchased from Strem Chemical (Newburyport, MA, USA). The $\left[\mathrm{P}_{66614}{ }^{+}\right]\left[\mathrm{Cl}^{-}\right] \mathrm{IL}$ was purified by dissolving $15 \mathrm{~g}$ of the $\mathrm{IL}$ in $50 \mathrm{~mL}$ of acetonitrile and washing 5 times with $10 \mathrm{~mL}$ of hexane. Acetonitrile was then removed by roto-evaporation and the purified IL was dried overnight under vacuum at room temperature. Manganese(II) chloride tetrahydrate was also dried under vacuum for 3 days at room temperature to remove water before use. All other chemicals were used as received.

\subsection{Instrumentation}

Nuclear magnetic resonance (NMR) spectra $\left({ }^{1} \mathrm{H}\right.$ and $\left.{ }^{13} \mathrm{C}\right)$ were acquired via a Bruker $500 \mathrm{MHz}$ spectrometer. Elemental analysis was obtained using a PerkinElmer 2100 Series II CHN/S Analyzer (Waltham, MA, USA). Thermogravimetric analysis (TGA) was performed using a Netzsch STA449 F1 thermogravimetric analyzer (Burlington, MA, USA). All samples were loaded in platinum pans and heated at a rate of $5{ }^{\circ} \mathrm{C} \min ^{-1}$ under an argon flow of $20 \mathrm{~mL} \mathrm{~min}^{-1}$. A Brookfield DV1 cone and plate viscometer with a CPA-51Z cone spindle at $65{ }^{\circ} \mathrm{C}$ was used to measure the viscosity of the MILs. Melting points were recorded by using a Mel-Temp II melting point apparatus (Dubuque, IA, USA). Magnetic measurements were performed using Quantum Design Superconducting Quantum Interference Device (SQUID) magnetometer, model MPMS XL-7. Magnetization as a function of temperature was measured between 300 and $2 \mathrm{~K}$ in $20 \mathrm{kOe}$ applied magnetic field. Thermal stability measurements were obtained by using the MILs as stationary phases in gas chromatography (GC) to determine the onset decomposition temperature. ${ }^{33}$ An Agilent Technologies 6850 GC (Santa Clara, CA, USA) with a flame ionization detector (FID) was used for thermal stability measurements. All MILs were coated on a $3 \mathrm{~m}$ untreated silica capillary with a $0.28 \mu \mathrm{m}$ film thickness. A temperature program, starting from $40{ }^{\circ} \mathrm{C}$ and increased to $350{ }^{\circ} \mathrm{C}$ at a rate of $1{ }^{\circ} \mathrm{C} \mathrm{min}{ }^{-1}$, was employed in all experiments.

\subsection{MIL synthesis}

MILs 1-24 were synthesized following a previously reported procedure, ${ }^{30}$ with some modifications, as shown in Scheme 1. Firstly, 10 mmol of $\mathrm{T}_{\mathrm{h}}$ tfacac, $\mathrm{N}_{\mathrm{p}}$ tfacac, $\mathrm{P}_{\mathrm{h}}$ tfacac, or tfacac were dissolved in acetone and a rubber septum used to seal the round bottom flask. An equimolar amount of ammonium hydroxide was then added dropwise to the reaction mixture and allowed to 


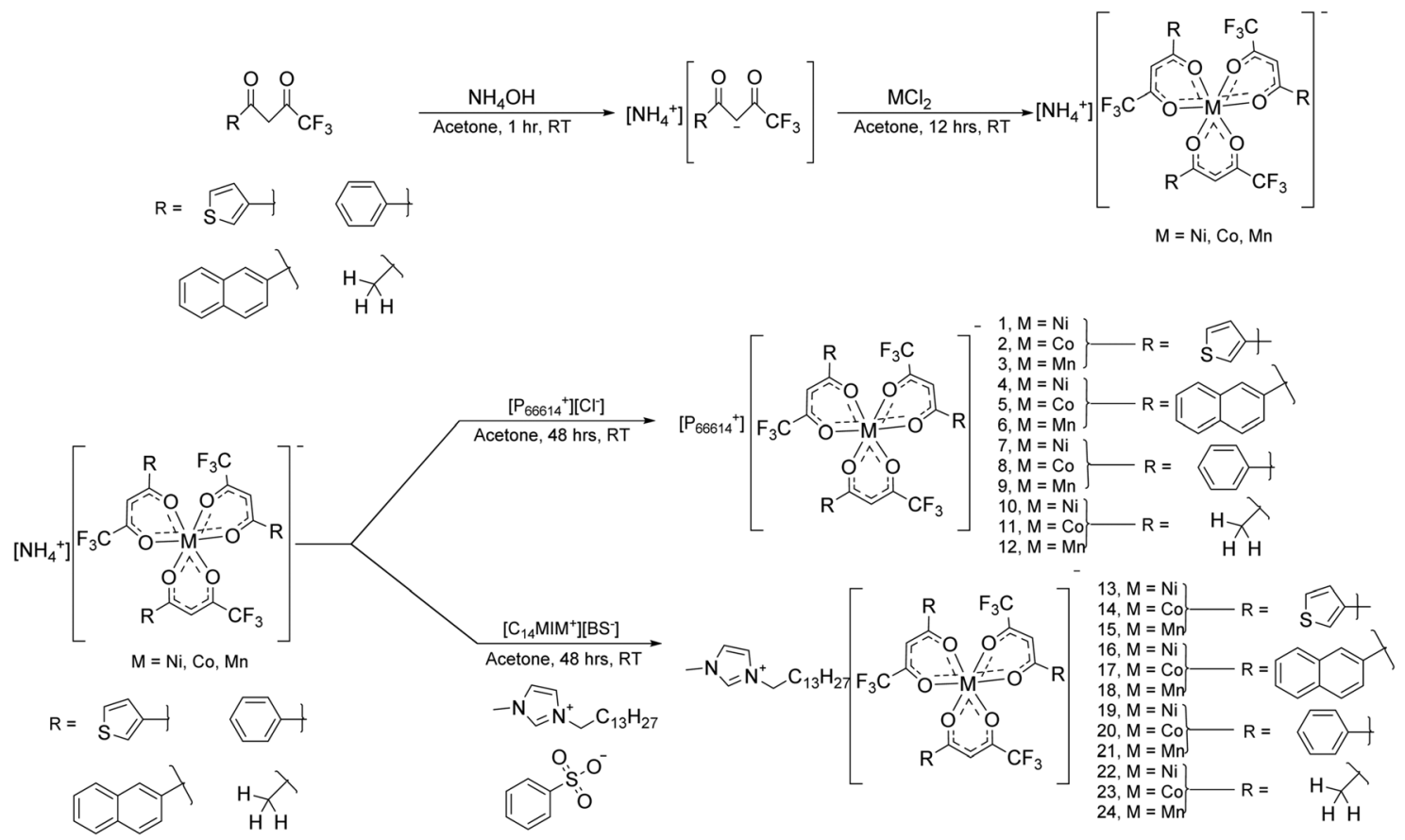

Scheme 1 Synthesis of transition metal ionic liquids with varying acetylacetone-based ligands and cations.

stir for $1 \mathrm{~h}$. Then, $3.3 \mathrm{mmol}$ of nickel(II) chloride, cobalt(II) chloride or manganese(II) chloride were added to the reaction mixture and allowed to stir overnight at room temperature. The solvent was then evaporated by roto-evaporation and the product dissolved in diethyl ether. Purification was performed by washing several times with $5 \mathrm{~mL}$ aliquots of water until the $\mathrm{AgNO}_{3}$ test yielded no precipitate for MILs 4-12 and 16-24. MILs 1-3 and 13-15 were dissolved in acetone and subsequently filtered to remove ammonium chloride. The ammonium salts of all MILs were dried overnight in a vacuum oven after evaporation of acetone. Ion exchange was carried out by metathesis reaction with either $\left[\mathrm{P}_{66614}{ }^{+}\right]\left[\mathrm{Cl}^{-}\right]$or $\left[\mathrm{C}_{14} \mathrm{MIM}^{+}\right]\left[\mathrm{BS}^{-}\right]$. The final product was dissolved in diethyl ether and washed with several $5 \mathrm{~mL}$ aliquots of water until no precipitate was observed via the $\mathrm{AgNO}_{3}$ test. Diethyl ether was evaporated by roto-evaporation and the purified MILs were dried in a vacuum oven for $48 \mathrm{~h}$ at room temperature. All MILs were subsequently characterized by elemental analysis.

\subsection{MIL characterization}

The following data describes the physical appearance of the MILs at room temperature and provides the elemental analysis data for all synthesized MILs:

MIL 1. Dark green, highly viscous liquid. Elemental analysis calcd (\%) for $\mathrm{C}_{56} \mathrm{H}_{80} \mathrm{~F}_{9} \mathrm{NiO}_{6} \mathrm{PS}_{3}$ : C, 55.77; $\mathrm{H}, 6.69$; found: $\mathrm{C}$, $55.76 ; \mathrm{H}, 6.65$.

MIL 2. Dark red, highly viscous liquid. Elemental analysis calcd (\%) for $\mathrm{C}_{56} \mathrm{H}_{80} \mathrm{~F}_{9} \mathrm{CoO}_{6} \mathrm{PS}_{3}$ : C, 55.76; $\mathrm{H}, 6.68$; found: $\mathrm{C}$, $55.60 ; \mathrm{H}, 6.51$.

MIL 3. Dark yellow, highly viscous liquid. Elemental analysis calcd (\%) for $\mathrm{C}_{56} \mathrm{H}_{80} \mathrm{~F}_{9} \mathrm{MnO}_{6} \mathrm{PS}_{3}$ : C, 55.94; $\mathrm{H}, 6.71$; found: $\mathrm{C}$, $56.77 ; \mathrm{H}, 6.75$.
MIL 4. Dark green, highly viscous liquid. Elemental analysis calcd (\%) for $\mathrm{C}_{74} \mathrm{H}_{92} \mathrm{~F}_{9} \mathrm{NiO}_{6} \mathrm{P}$ : C, 66.42; $\mathrm{H}, 6.93$; found: $\mathrm{C}$, $66.20 ; \mathrm{H}, 7.10$.

MIL 5. Dark red, highly viscous liquid. Elemental analysis calcd (\%) for $\mathrm{C}_{74} \mathrm{H}_{92} \mathrm{~F}_{9} \mathrm{CoO}_{6} \mathrm{P}$ : C, 66.41; H, 6.93; found: C, 65.89; H, 7.31.

MIL 6. Dark yellow, highly viscous liquid. Elemental analysis calcd (\%) for $\mathrm{C}_{74} \mathrm{H}_{92} \mathrm{~F}_{9} \mathrm{MnO}_{6} \mathrm{P}$ : C, 66.61; $\mathrm{H}, 6.95$; found: $\mathrm{C}$, $66.12 ; \mathrm{H}, 7.15$.

MIL 7. Dark green, viscous liquid. Elemental analysis calcd (\%) for $\mathrm{C}_{62} \mathrm{H}_{86} \mathrm{~F}_{9} \mathrm{NiO}_{6} \mathrm{P}: \mathrm{C}, 62.68 ; \mathrm{H}, 7.30$; found: $\mathrm{C}, 62.65 ; \mathrm{H}, 7.13$.

MIL 8. Dark red, viscous liquid. Elemental analysis calcd (\%) for $\mathrm{C}_{62} \mathrm{H}_{86} \mathrm{~F}_{9} \mathrm{CoO}_{6} \mathrm{P}: \mathrm{C}, 62.67 ; \mathrm{H}, 7.30$; found: $\mathrm{C}, 63.31 ; \mathrm{H}, 7.57$.

MIL 9. Dark yellow, viscous liquid. Elemental analysis calcd (\%) for $\mathrm{C}_{62} \mathrm{H}_{86} \mathrm{~F}_{9} \mathrm{MnO}_{6} \mathrm{P}$ : C, 62.88; $\mathrm{H}, 7.32$; found: $\mathrm{C}, 62.82 ; \mathrm{H}, 7.31$.

MIL 10. Dark green, viscous liquid. Elemental analysis calcd (\%) for $\mathrm{C}_{47} \mathrm{H}_{80} \mathrm{~F}_{9} \mathrm{NiO}_{6} \mathrm{P}$ : C, 56.35; H, 8.05; found: C, 57.19; H, 8.44.

MIL 11. Dark red, viscous liquid. Elemental analysis calcd (\%) for $\mathrm{C}_{47} \mathrm{H}_{80} \mathrm{~F}_{9} \mathrm{CoO}_{6} \mathrm{P}$ : C, 56.35; H, 8.05; found: C, 57.34; H, 7.96.

MIL 12. Dark yellow, viscous liquid. Elemental analysis calcd (\%) for $\mathrm{C}_{47} \mathrm{H}_{80} \mathrm{~F}_{9} \mathrm{MnO}_{6} \mathrm{P}$ : C, 56.56; H, 8.08; found: C, 56.92; H, 8.11.

MIL 13. Dark green, sticky solid. Elemental analysis calcd (\%) for $\mathrm{C}_{42} \mathrm{H}_{47} \mathrm{~F}_{9} \mathrm{~N}_{2} \mathrm{NiO}_{6} \mathrm{~S}_{3}$ : C, 50.36; $\mathrm{H}, 4.73 ; \mathrm{N}, 2.80$; found: $\mathrm{C}, 50.23$; $\mathrm{H}, 4.50 ; \mathrm{N}, 2.96$.

MIL 14. Dark red, sticky solid. Elemental analysis calcd (\%) for $\mathrm{C}_{42} \mathrm{H}_{47} \mathrm{~F}_{9} \mathrm{~N}_{2} \mathrm{CoO}_{6} \mathrm{~S}_{3}$ : C, 50.35; H, 4.73; N, 2.80; found: C, $50.05 ; \mathrm{H}, 4.54 ; \mathrm{N}, 2.50$.

MIL 15. Dark yellow, sticky solid. Elemental analysis calcd (\%) for $\mathrm{C}_{42} \mathrm{H}_{47} \mathrm{~F}_{9} \mathrm{~N}_{2} \mathrm{MnO}_{6} \mathrm{~S}_{3}$ : C, 50.55; H, 4.75; N, 2.81; found: C, $50.25 ; \mathrm{H}, 4.59 ; \mathrm{N}, 2.65$.

MIL 16. Dark green, solid. Elemental analysis calcd (\%) for $\mathrm{C}_{60} \mathrm{H}_{59} \mathrm{~F}_{9} \mathrm{~N}_{2} \mathrm{NiO}_{6}: \mathrm{C}, 63.56 ; \mathrm{H}, 5.25 ; \mathrm{N}, 2.47$; found: $\mathrm{C}, 63.71 ; \mathrm{H}$, $5.00, \mathrm{~N}, 2.20$. 
MIL 17. Dark red, solid. Elemental analysis calcd (\%) for $\mathrm{C}_{60} \mathrm{H}_{59} \mathrm{~F}_{9} \mathrm{~N}_{2} \mathrm{CoO}_{6}$ : C, 63.55; H, 5.24; N, 2.47; found: C, 63.15; H, 5.09, N, 2.40.

MIL 18. Dark yellow, solid. Elemental analysis calcd (\%) for $\mathrm{C}_{60} \mathrm{H}_{59} \mathrm{~F}_{9} \mathrm{~N}_{2} \mathrm{MnO}_{6}$ : C, 63.77; $\mathrm{H}, 5.26 ; \mathrm{N}, 2.48$; found: $\mathrm{C}, 63.59 ; \mathrm{H}$, $5.08, \mathrm{~N}, 2.24$.

MIL 19. Dark green, highly viscous liquid. Elemental analysis calcd (\%) for $\mathrm{C}_{48} \mathrm{H}_{53} \mathrm{~F}_{9} \mathrm{~N}_{2} \mathrm{NiO}_{6}$ : C, 58.61; H, 5.43; N, 2.85; found: C, 58.67; H, 5.35; N, 2.72.

MIL 20. Dark red, sticky solid. Elemental analysis calcd (\%) for $\mathrm{C}_{48} \mathrm{H}_{53} \mathrm{~F}_{9} \mathrm{~N}_{2} \mathrm{CoO}_{6}$ : C, 58.60; $\mathrm{H}, 5.43 ; \mathrm{N}, 2.85$; found: $\mathrm{C}, 58.72$; $\mathrm{H}, 5.44 ; \mathrm{N}, 2.77$.

MIL 21. Dark yellow, sticky solid. Elemental analysis calcd (\%) for $\mathrm{C}_{48} \mathrm{H}_{53} \mathrm{~F}_{9} \mathrm{~N}_{2} \mathrm{MnO}_{6}$ : C, 58.84; $\mathrm{H}, 5.45 ; \mathrm{N}, 2.85$; found: $\mathrm{C}, 59.06 ; \mathrm{H}$, 5.76; N, 3.13.

MIL 22. Dark green, viscous liquid. Elemental analysis calcd (\%) for $\mathrm{C}_{33} \mathrm{H}_{47} \mathrm{~F}_{9} \mathrm{~N}_{2} \mathrm{NiO}_{6}$ : C, 49.71; $\mathrm{H}, 5.94 ; \mathrm{N}, 3.51$; found: C, 48.97; $\mathrm{H}$, $5.71 ; \mathrm{N}, 3.72$.

MIL 23. Dark red, viscous liquid. Elemental analysis calcd (\%) for $\mathrm{C}_{33} \mathrm{H}_{47} \mathrm{~F}_{9} \mathrm{~N}_{2} \mathrm{CoO}_{6}$ : C, 49.69; H, 5.94; N, 3.51; found: C, 49.08; H, $5.63 ; \mathrm{N}, 3.70$.

MIL 24. Dark yellow, viscous liquid. Elemental analysis calcd (\%) for $\mathrm{C}_{33} \mathrm{H}_{47} \mathrm{~F}_{9} \mathrm{~N}_{2} \mathrm{MnO}_{6}$ : C, 49.94; $\mathrm{H}, 5.97$; N, 3.53; found: C, 49.79; $\mathrm{H}$, 5.88; N, 3.90.

\section{Results and discussion}

\subsection{Preparation of MILs}

The general synthetic strategy employed in this study is largely based on a previous study. ${ }^{30}$ Acetylacetone-based ligands have been extensively studied for the preparation of coordination complexes with metals. ${ }^{32,34,35}$ In this study, carefully chosen fluorinated acetylacetone-based ligands were employed in order to modulate the hydrophobicity of the MILs, ${ }^{32}$ as the utility of previous iron-based MILs was limited due to their tendency to undergo hydrolysis in water. ${ }^{29,36}$ To increase the hydrophobicity of MILs, imidazolium or asymmetric phosphonium cations containing long alkyl chain substituents were employed. The alkyl chain length and asymmetry in the cation structure plays a pivotal role in the MILs being liquid at room temperature. ${ }^{31}$

The first step in the synthesis of the MILs evaluated in this study involves preparing the ammonium salt of the transition metals, in which three acetylacetone-based ligands are coordinated to different transition metal centers. A one pot synthetic approach was used, in which acetylacetone-based ligands were dissolved in acetone followed by the dropwise addition of ammonium hydroxide via syringe. Upon addition of ammonium hydroxide, a white vapor was formed as the result of an acid-base reaction between ammonium hydroxide and the acetylacetone-based ligand. The reaction flask was properly sealed to ensure no vapors were lost, which can detrimentally affect the stoichiometry of the reaction. The transition metal halide salt was subsequently added after the vapor was observed to settle.

The ammonium salts of all transition metals (Ni(II), Co(II), and $\mathrm{Mn}(\mathrm{II})$ ) with $\mathrm{N}_{\mathrm{p}}$ tfacac, $\mathrm{P}_{\mathrm{h}}$ tfacac and tfacac ligands were purified by dissolution in diethyl ether and washed several times with water, until a $\mathrm{AgNO}_{3}$ test yielded no visible precipitate. However, the solubility of ammonium salts containing $\mathrm{T}_{\mathrm{h}}$ tfacac ligands in diethyl ether was observed to be very low. Therefore, a different strategy involving the dissolution of the product in acetone and subsequently filtering to remove insoluble ammonium chloride was employed. The second step of the reaction involved a metathesis reaction of the purified ammonium salts with either $\left[\mathrm{C}_{14} \mathrm{MIM}^{+}\right]\left[\mathrm{BS}^{-}\right]$or $\left[\mathrm{P}_{66614}^{+}\right]\left[\mathrm{Cl}^{-}\right]$.

\subsection{Thermal stability}

High temperature applications of hexfluoroacetylacetone-based MILs requiring high thermal stability have been largely limited by the weak metal-ligand interactions. Pierson et al. compared the thermal stabilities of $\left[\mathrm{P}_{66614}{ }^{+}\right]\left[\mathrm{Cl}^{-}\right]$and hexafluoroacetylacetonate-based MILs containing $\mathrm{Co}$ (II), $\mathrm{Mn}$ (II) and Ni(II) transition metal centers paired with the $\left[\mathrm{P}_{66614}{ }^{+}\right]$cation. Using GC to measure the thermal stability, it was found that the metal-ligand complex limited the thermal stability of the MILs. ${ }^{30}$ In this study, different acetylacetone-based ligands featuring phenyl, thiophenyl, and naphthyl moieties were complexed with varying transition metals, paired with phosphonium and alkylimidazolium-based cations, and subsequently examined to study their effect on thermal stability. To study the onset temperature of MIL volatilization/ decomposition, the thermal stability was determined by GC coupled to a FID, which is capable of detecting liberated volatilization/decomposition products from the MIL. ${ }^{33}$

The Ni-based MILs prepared in this study were used to examine the ligand and cation effects on thermal stability. Thermal stability diagrams of all Ni-based MILs are shown in Fig. 1. The thermal stabilities were observed to range from approximately $130{ }^{\circ} \mathrm{C}$ to $260{ }^{\circ} \mathrm{C}$. It was observed that the thermal stability could

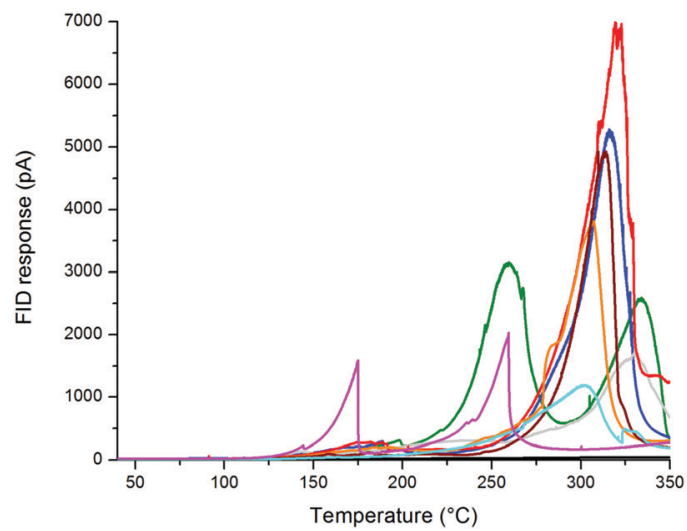

Fig. 1 Thermal stability diagram of $\mathrm{Ni}$-containing MILs with varying ligand structures obtained using GC with an FID. The columns containing the MILs as a stationary phase were subjected to the following temperature program: $40^{\circ} \mathrm{C}$ to $350^{\circ} \mathrm{C}$ at a rate of $1^{\circ} \mathrm{C} \mathrm{min}{ }^{-1}$. The increased response is due to volatilization/decomposition products exiting the chromatographic column and entering the detector. Blank untreated capillary (Black line), $\left[\mathrm{C}_{14} \mathrm{MIM}^{+}\right]\left[\mathrm{Ni}\left(\mathrm{P}_{\mathrm{h}} \mathrm{tfacac}_{3}\right)_{3}^{-}\right]$(orange line), $\left[\mathrm{P}_{66614}{ }^{+}\right]\left[\mathrm{Ni}\left(\mathrm{P}_{\mathrm{h}} \mathrm{tfacac}\right)_{3}{ }^{-}\right]$(red line), $\left[\mathrm{P}_{66614}{ }^{+}\right]\left[\mathrm{Ni}\left(\mathrm{T}_{\mathrm{h}} \mathrm{tfacac}_{3}{ }^{-}\right]\right.$(brown line), $\left[\mathrm{C}_{14} \mathrm{MIM}^{+}\right]\left[\mathrm{Ni}\left(\mathrm{T}_{\mathrm{h}} \mathrm{tfacac}\right)_{3}{ }^{-}\right]$(sky blue line), $\left[\mathrm{P}_{66614}{ }^{+}\right]\left[\mathrm{Ni}\left(\mathrm{N}_{\mathrm{p}} \mathrm{tfacac}_{3}{ }_{3}^{-}\right]\right.$(blue line), $\left[\mathrm{C}_{14} \mathrm{MIM}^{+}\right]\left[\mathrm{Ni}\left(\mathrm{N}_{\mathrm{p}}\right.\right.$ tfacac) $\left.{ }_{3}^{-}\right]$(grey line), $\left[\mathrm{C}_{14} \mathrm{MIM}^{+}\right]\left[\mathrm{Ni}(\mathrm{tfacac})_{3}{ }^{-}\right]$(pink line) and $\left[\mathrm{P}_{66614}{ }^{+}\right]\left[\mathrm{Ni}(\mathrm{tfacac})_{3}{ }^{-}\right]$(green line). 
be increased through the incorporation of aromatic moieties to the ligand structure. For example, the thermal stability of MIL 10 $\left(\left[\mathrm{P}_{66614}{ }^{+}\right]\left[\mathrm{Ni}(\mathrm{II})(\mathrm{tfacac})_{3}{ }^{-}\right]\right)$, which lacks aromatic moieties in the ligand structure, was observed to be approximately $160{ }^{\circ} \mathrm{C}$. Similarly, the thermal stability of $\mathrm{MIL} 22\left(\left[\mathrm{C}_{14} \mathrm{MIM}^{+}\right]\left[\mathrm{Ni}(\mathrm{II})(\text { tfacac })_{3}{ }^{-}\right]\right)$was found to be approximately $130{ }^{\circ} \mathrm{C}$. The thermal stability of MIL 1 $\left(\left[\mathrm{P}_{66614}{ }^{+}\right]\left[\mathrm{Ni}(\mathrm{II})\left(\mathrm{T}_{\mathrm{h}} \mathrm{tfacac}\right)_{3}{ }^{-}\right]\right)$, containing thiophenyl moieties in the ligand structure, was found to be approximately $260{ }^{\circ} \mathrm{C}$. Furthermore, the thermal stabilities of MILs containing phenyl, thiophenyl, and naphthyl moieties were found to be similar and within the range of $230{ }^{\circ} \mathrm{C}$ to $260{ }^{\circ} \mathrm{C}$.

To gain further insight into the thermal-degradation of the MILs, TGA was performed (see Fig. S1 and S2 of the ESI $\dagger$ ) using a temperature range from $40{ }^{\circ} \mathrm{C}$ to $500{ }^{\circ} \mathrm{C}$. MIL 10 exhibited a multistep decomposition pathway in which mass loss was observed at temperatures of approximately $150{ }^{\circ} \mathrm{C}, 290{ }^{\circ} \mathrm{C}$ and $400{ }^{\circ} \mathrm{C}$. Meanwhile, MIL 7 exhibited decomposition at approximately $310{ }^{\circ} \mathrm{C}$ and $420{ }^{\circ} \mathrm{C}$. When the TGA data is compared to thermal stability data acquired by GC-FID in Fig. 1, two peaks can be observed for MIL 10, while the other MILs showed only one decomposition peak below $350{ }^{\circ} \mathrm{C}$. TGA analysis provides evidence that all MILs appear to decompose via a multi-step decomposition process. The GC method provides the most precise thermal stability since it can detect very small levels of degradation compared to TGA. This is due to the fact that very low heating increments are more easily implemented $\left(1^{\circ} \mathrm{C} \mathrm{min}^{-1}\right)$ in GC compared to common heating rates in TGA $\left(5^{\circ} \mathrm{C} \mathrm{min}^{-1}\right)$, which often leads to an overestimation of thermal stability. ${ }^{37}$

\subsection{Magnetic susceptibility}

Magnetic susceptibility is an intrinsic feature of MILs that differentiates them from traditional ILs. All of the MILs examined in this work contain a transition metal center possessing unpaired electrons. When these MILs are placed in an external magnetic field, the magnetic moments originating from unpaired electrons of the $3 \mathrm{~d}$ orbitals rotate along the magnetic field direction exhibiting paramagnetism. According to Curie's law, the magnetic susceptibility $(\chi)$ of a paramagnetic material is inversely proportional to temperature $(T)$. An analysis of the linear relationship between the reciprocal susceptibility and temperature also is employed to reveal the magnetic characteristics of MILs, such as effective magnetic moment. The results obtained in this study show that magnetic behavior of all MILs follows the Curie-Weiss law, $\chi(T)=C /\left(T-\theta_{\mathrm{p}}\right)$, where $\chi$ is magnetic susceptibility, $C$ is Curie constant, related to the value of effective moment, and $\theta_{\mathrm{p}}$ is a Weiss constant, which accounts for the presence of exchange interactions.

Magnetic susceptibility measurements were carried out on eight Ni MILs featuring four different ligands and two different cations. Fig. 2 shows representative Curie-Weiss curve for MIL $19\left(\left[\mathrm{C}_{14} \mathrm{MIM}^{+}\right]\left[\mathrm{Ni}\left(\mathrm{P}_{\mathrm{h}} \text { tfacac }\right)_{3}{ }^{-}\right]\right) . \mathrm{Ni}(\mathrm{II})$ is a d ${ }^{8}$ system which forms octahedral complexes, ${ }^{38}$ with a theoretical magnetic moment of $2.8 \mu_{\mathrm{B}} / \mathrm{Ni}$ atom. Experimental values obtained for Ni(II)-based MILs (see Table 1) were found to be in agreement with the aforementioned theoretical value and previously reported data for other acetylacetone-based MILs. ${ }^{30,38,39}$

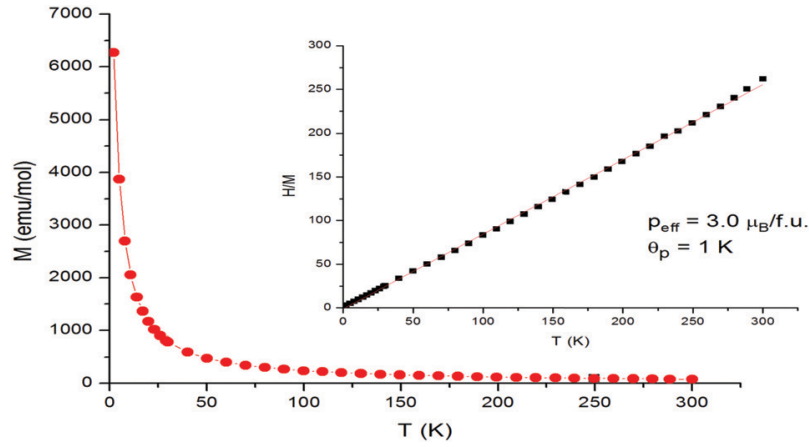

Fig. 2 Magnetization of the $\left[\mathrm{C}_{14} \mathrm{MIM}^{+}\right]\left[\mathrm{Ni}\left(\mathrm{P}_{\mathrm{h}} \text { tfacac }\right)_{3}{ }^{-}\right] \mathrm{MIL}$ as a function of temperature in applied magnetic field of $\mathrm{H}=20 \mathrm{kOe}$ between 2 and $300 \mathrm{~K}$. The inset shows the Curie-Weiss fit of reciprocal magnetic susceptibility vs. temperature.

Table 1 Effective magnetic moment in Bohr magnetons $\left(\mu_{\mathrm{B}}\right)$ for selected MILs examined in this study determined by SQUID magnetometer

\begin{tabular}{|c|c|c|}
\hline MIL no. & MIL abbreviation & $p_{\text {eff }}\left(\mu_{\mathrm{B}}\right)$ per f.u. \\
\hline MIL 1 & {$\left[\mathrm{P}_{66614}{ }^{+}\right]\left[\mathrm{Ni}\left(\mathrm{T}_{\mathrm{h}} \mathrm{tfacac}\right)_{3}{ }^{-}\right]$} & 3.1 \\
\hline MIL 4 & {$\left[\mathrm{P}_{66614}{ }^{+}\right]\left[\mathrm{Ni}\left(\mathrm{N}_{\mathrm{p}} \mathrm{tfacac}\right)_{3}{ }^{-}\right]$} & 2.6 \\
\hline MIL 7 & {$\left[\mathrm{P}_{66614}{ }^{+}\right]\left[\mathrm{Ni}\left(\mathrm{P}_{\mathrm{h}} \mathrm{tfacac}\right)^{-}\right]$} & 2.7 \\
\hline MIL 10 & {$\left[\mathrm{P}_{66614}{ }^{+}\right]\left[\mathrm{Ni}(\mathrm{tfacac})_{3}^{-}\right]$} & 2.4 \\
\hline MIL 13 & {$\left[\mathrm{C}_{14} \mathrm{MIM}^{+}\right]\left[\mathrm{Ni}\left(\mathrm{T}_{\mathrm{h}} \mathrm{tfacac}_{3}{ }^{-}\right]\right.$} & 3.1 \\
\hline MIL 16 & {$\left[\mathrm{C}_{14} \mathrm{MIM}^{+}\right]\left[\mathrm{Ni}\left(\mathrm{N}_{\mathrm{p}} \mathrm{tfacac}_{3_{3}}{ }^{-}\right.\right.$} & 2.8 \\
\hline MIL 19 & {$\left[\mathrm{C}_{14} \mathrm{MIM}^{+}\right]\left[\mathrm{Ni}\left(\mathrm{P}_{\mathrm{h}} \text { tfacac }\right)_{3}{ }^{-}\right.$} & 3.0 \\
\hline MIL 22 & {$\left[\mathrm{C}_{14} \mathrm{MIM}^{+}\right]\left[\mathrm{Ni}\left(\mathrm{tfacac}_{3}{ }^{-}\right]\right.$} & 2.5 \\
\hline MIL 8 & {$\left[\mathrm{P}_{66614}{ }^{+}\right]\left[\mathrm{Co}\left(\mathrm{P}_{\mathrm{h}} \mathrm{tfacac}\right)_{3}{ }^{-}\right.$} & 4.3 \\
\hline MIL 20 & {$\left[\mathrm{C}_{14} \mathrm{MIM}^{+}\right]\left[\mathrm{Co}\left(\mathrm{P}_{\mathrm{h}} \mathrm{tfacac}\right)_{3}^{-}\right]$} & 4.5 \\
\hline MIL 9 & {$\left[\mathrm{P}_{66614}{ }^{+}\right]\left[\mathrm{Mn}\left(\mathrm{P}_{\mathrm{h}} \mathrm{tfacac}_{3_{3}}{ }^{-}\right]\right.$} & 5.4 \\
\hline MIL 21 & {$\left[\mathrm{C}_{14} \mathrm{MIM}^{+}\right]\left[\mathrm{Mn}\left(\mathrm{P}_{\mathrm{h}} \mathrm{tfacac}\right)_{3}^{-}\right]$} & 5.6 \\
\hline
\end{tabular}

The magnetic susceptibility of two Mn-based MILs and two Co-based MILs was also measured to study the effect of different metal center on the magnetic behavior. Fig. 3 shows the Curie-Weiss plot for MIL $21\left(\left[\mathrm{C}_{14} \mathrm{MIM}^{+}\right]\left[\mathrm{Mn}\left(\mathrm{P}_{\mathrm{h}} \mathrm{tfacac}\right)_{3}{ }^{-}\right]\right)$. Since $\mathrm{Mn}$ (II) is a $\mathrm{d}^{5}$ system and $\mathrm{Co}(\mathrm{II})$ is a $\mathrm{d}^{7}$ system, both of these transition metals could exhibit low or high spin configuration in octahedral complexes based upon the type of ligand. Weak field ligands result in high spin complexes while strong field

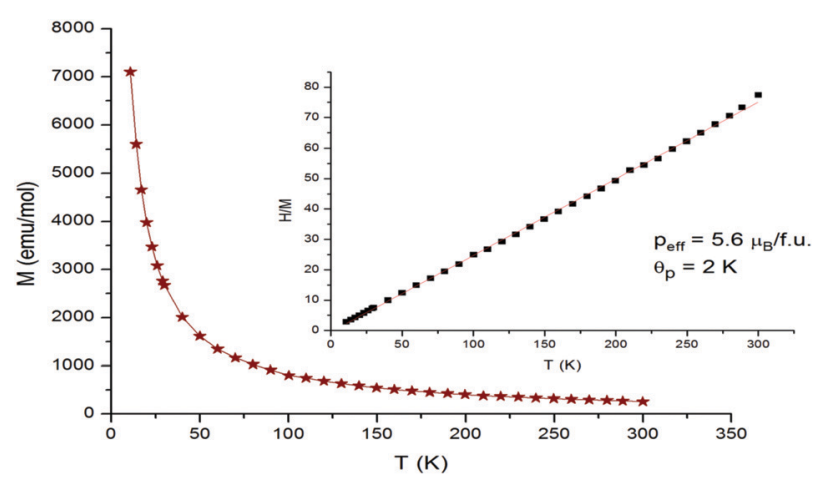

Fig. 3 Magnetization of the $\left[\mathrm{C}_{14} \mathrm{MIM}^{+}\right]\left[\mathrm{Mn}\left(\mathrm{P}_{\mathrm{h}} \text { tfacac }\right)_{3}^{-}\right] \mathrm{MIL}$ as a function of temperature in applied magnetic field of $\mathrm{H}=20 \mathrm{kOe}$ between 2 and $300 \mathrm{~K}$. The inset shows the Curie-Weiss fit of reciprocal magnetic susceptibility vs. temperature. 
ligands give low spin complexes. ${ }^{40} \mathrm{~A}$ magnetic moment of $5.6 \mu_{\mathrm{B}} / \mathrm{Mn}$ was observed for the $\left[\mathrm{P}_{66614}{ }^{+}\right]\left[\mathrm{Mn}\left(\mathrm{P}_{\mathrm{h}} \mathrm{tfacac}\right)_{3}{ }^{-}\right] \mathrm{MIL}$ while the $\left[\mathrm{P}_{66614}{ }^{+}\right]\left[\mathrm{Co}\left(\mathrm{P}_{\mathrm{h}} \mathrm{tfacac}\right)_{3}{ }^{-}\right]$MIL gave a value of $4.5 \mu_{\mathrm{B}} / \mathrm{Co}$, showing that both of these transition metals form high spin octahedral complexes. ${ }^{38,41}$ High spin configuration of $\mathrm{Mn}$ (II) and $\mathrm{Co}(\mathrm{II})$ can be explained by the coordination of metal centers with acetylacetone-based, weak field ligands. ${ }^{42}$ The Curie-Weiss plots for the remaining MILs $(\mathbf{1}, 4,7, \mathbf{8}, \mathbf{9}, \mathbf{1 0}, \mathbf{1 3}, \mathbf{1 6}, 20$, and 22) are provided in Fig. S3-S12 of the ESI. $\dagger$ The effective magnetic moments $\left(p_{\text {eff }}\right)$ in Bohr magnetons $\left(\mu_{\mathrm{B}}\right)$ of all studied MILs calculated per formula unit/transition metal atom are presented in Table 1.

\subsection{Viscosity}

The viscosity of MILs is an important feature that often dictates their use in a number of applications. Low viscosity MILs are extremely useful in applications requiring extensive fluid manipulation. ${ }^{4}$ However, higher viscosity MILs serve important purposes in other applications that require mechanically stable liquids ${ }^{29}$ Previously reported MILs, such as trihexyl(tetradecyl)phosphonium tetrachloromanganate(II) $\left(\left[\mathrm{P}_{66614}{ }^{+}\right]_{2}\left[\mathrm{MnCl}_{2}{ }^{2-}\right]\right)$, exhibited high viscosity values of approximately $75230 \mathrm{cP}$ at $25{ }^{\circ} \mathrm{C}^{27}$ On the contrary, low viscosity MILs such as 1-ethyl-3methylimidazolium tetrachloroferrate(III) $\left(\left[\mathrm{EMIM}^{+}\right]\left[\mathrm{FeCl}_{4}{ }^{-}\right]\right)$and
$\left[\mathrm{BMIM}^{+}\right]\left[\mathrm{FeCl}_{4}^{-}\right]$feature viscosities of around $18 \mathrm{cP}$ and $34 \mathrm{cP}$, respectively. ${ }^{28}$ However, these MILs were not water stable due to hydrolysis, limiting their overall potential applications. ${ }^{29,36}$

MILs possessing a broad range of viscosities were synthesized in this study. All viscosities were measured at a temperature of $65{ }^{\circ} \mathrm{C}$ to enable the determination of higher viscosity MILs. As shown in Table 2, the lowest viscosities were observed for MILs containing anions based on the tfacac ligands where viscosities ranged from $119 \mathrm{cP}$ to $172 \mathrm{cP}$ for MILs containing the phosphonium cation and from $845 \mathrm{cP}$ to $2209 \mathrm{cP}$ for MILs containing the imidazolium cation. The viscosity of MILs were observed to significantly increase when ligands containing aromatic moieties were incorporated into the chemical structure. For example, MILs possessing the $\mathrm{P}_{\mathrm{h}}$ tfacac ligand had viscosities ranging from 1139 $\mathrm{cP}$ to $4108 \mathrm{cP}$ for those containing the phosphonium cation, and from $40240 \mathrm{cP}$ to $49542 \mathrm{cP}$ for MILs containing the imidazolium cation. MILs containing $\mathrm{N}_{\mathrm{p}}$ tfacac ligands were found to possess the highest viscosities when paired with the phosphonium cation, ranging from $42110 \mathrm{cP}$ to $48920 \mathrm{cP}$. MILs 13 and 16 were observed to be solids, and their melting points were determined to be approximately $69^{\circ} \mathrm{C}$ and $88{ }^{\circ} \mathrm{C}$, respectively. The remaining MILs containing the imidazolium cation were too viscous to be measured as they exceeded the maximum range of viscometer (e.g. $170000 \mathrm{cP}$ ). These results highlight a very significant difference

Table 2 Viscosity measurements of 24 MILs examined in this study using a Brookfield DV 1 viscometer with $\mathrm{CPA}-51 \mathrm{Z}$ cone spindle at $65^{\circ} \mathrm{C}$

\begin{tabular}{|c|c|c|c|}
\hline Compound abbreviation & Viscosity (cP) & Compound abbreviation & Viscosity (cP) \\
\hline 1: $\left[\mathrm{P}_{66614}{ }^{+}\right]\left[\mathrm{Ni}\left(\mathrm{T}_{\mathrm{h}} \mathrm{tfacac}\right)_{3}{ }^{-}\right]$ & 3521 & 13: $\left[\mathrm{C}_{14} \mathrm{MIM}^{+}\right]\left[\mathrm{Ni}\left(\mathrm{T}_{\mathrm{h}} \mathrm{tfacac}\right)_{3}{ }^{-}\right]$ & $-a$ \\
\hline 2: $\left[\mathrm{P}_{66614}{ }^{+}\right]\left[\mathrm{Co}\left(\mathrm{T}_{\mathrm{h}} \mathrm{tfacac}\right)_{3}{ }^{-}\right]$ & 4747 & 14: $\left[\mathrm{C}_{14} \mathrm{MIM}^{+}\right]\left[\mathrm{Co}\left(\mathrm{T}_{\mathrm{h}} \mathrm{tfacac}_{3}{ }^{-}\right]\right.$ & $-b$ \\
\hline 3: $\left[\mathrm{P}_{66614}{ }^{+}\right]\left[\mathrm{Mn}\left(\mathrm{T}_{\mathrm{h}} \mathrm{tfacac}_{3}{ }^{-}\right.\right.$ & 5937 & 15: $\left[\mathrm{C}_{14} \mathrm{MIM}^{+}\right]\left[\mathrm{Mn}\left(\mathrm{T}_{\mathrm{h}} \text { tfacac }\right)_{3}{ }^{-}\right.$ & $-^{b}$ \\
\hline 4: $\left[\mathrm{P}_{66614}{ }^{+}\right]\left[\mathrm{Ni}\left(\mathrm{N}_{\mathrm{p}} \text { tfacac }\right)_{3}{ }^{-}\right.$ & 42110 & 16: $\left[\mathrm{C}_{14} \mathrm{MIM}^{+}\right]\left[\mathrm{Ni}\left(\mathrm{N}_{\mathrm{p}} \text { tfacac }\right)_{3}{ }^{-}\right.$ & $-^{a}$ \\
\hline 5: $\left[\mathrm{P}_{66614}{ }^{+}\right]\left[\mathrm{Co}\left(\mathrm{N}_{\mathrm{p}} \text { tfacac }\right)_{3}{ }^{-}\right.$ & 48920 & 17: $\left[\mathrm{C}_{14} \mathrm{MIM}^{+}\right]\left[\mathrm{Co}\left(\mathrm{N}_{\mathrm{p}} \text { tfacac }\right)_{3}\right.$ & $-^{b}$ \\
\hline 6: $\left[\mathrm{P}_{66614}{ }^{+}\right]\left[\mathrm{Mn}\left(\mathrm{N}_{\mathrm{p}} \text { tfacac }\right)_{3}{ }^{-}\right.$ & 46170 & 18: $\left[\mathrm{C}_{14} \mathrm{MIM}^{+}\right]\left[\mathrm{Mn}\left(\mathrm{N}_{\mathrm{p}} \text { tfacac }\right)_{3}{ }^{-}\right]$ & $-^{b}$ \\
\hline 7: $\left[\mathrm{P}_{66614}{ }^{+}\right]\left[\mathrm{Ni}\left(\mathrm{P}_{\mathrm{h}} \mathrm{tfacac}\right)^{-}\right]$ & 4108 & 19: $\left[\mathrm{C}_{14} \mathrm{MIM}^{+}\right]\left[\mathrm{Ni}\left(\mathrm{P}_{\mathrm{h}} \mathrm{tfacac}\right)_{3}{ }^{-}\right]$ & 49542 \\
\hline 8: $\left[\mathrm{P}_{66614}{ }^{+}\right]\left[\mathrm{Co}\left(\mathrm{P}_{\mathrm{h}} \mathrm{tfacac}\right)_{3}{ }^{-}\right.$ & 1916 & 20: $\left[\mathrm{C}_{14} \mathrm{MIM}^{+}\right]\left[\mathrm{Co}\left(\mathrm{P}_{\mathrm{h}} \mathrm{tfacac}\right)_{3}{ }^{-}\right.$ & 47120 \\
\hline 9: $\left[\mathrm{P}_{66614}{ }^{+}\right]\left[\mathrm{Mn}\left(\mathrm{P}_{\mathrm{h}} \mathrm{tfacac}\right)_{3}{ }^{-}\right.$ & 1139 & 21: $\left[\mathrm{C}_{14} \mathrm{MIM}^{+}\right]\left[\mathrm{Mn}\left(\mathrm{P}_{\mathrm{h}} \mathrm{tfacac}\right)_{3}{ }^{-}\right]$ & 40240 \\
\hline 10: $\left[\mathrm{P}_{66614}{ }^{+}\right]\left[\mathrm{Ni}(\text { tfacac })_{3}{ }^{-}\right]$ & 127 & 22: $\left[\mathrm{C}_{14} \mathrm{MIM}^{+}\right]\left[\mathrm{Ni}(\mathrm{tfacac})_{3}{ }^{-}\right.$ & 2060 \\
\hline 11: $\left[\mathrm{P}_{66614}{ }^{+}\right]\left[\mathrm{Co}(\text { tfacac })_{3}{ }^{-}\right]$ & 172 & 23: $\left[\mathrm{C}_{14} \mathrm{MIM}^{+}\right]\left[\mathrm{Co}(\mathrm{tfacac})_{3}{ }^{-}\right]$ & 2209 \\
\hline 12: $\left[\mathrm{P}_{66614}{ }^{+}\right]\left[\mathrm{Mn}(\text { tfacac })_{3}{ }^{-}\right]$ & 119 & 24: $\left[\mathrm{C}_{14} \mathrm{MIM}^{+}\right]\left[\mathrm{Mn}(\text { tfacac })_{3}{ }^{-}\right]$ & 845 \\
\hline
\end{tabular}

${ }^{a}$ MILs are solids at a temperature of $65{ }^{\circ} \mathrm{C} .{ }^{b}$ MILs had viscosity values that exceeded the maximum range of the instrument at $65{ }^{\circ} \mathrm{C}$.

Table 3 Solubility of all MILs examined in this study in ten different organic solvents

\begin{tabular}{|c|c|c|c|}
\hline Compound abbreviation & Solubility & Compound abbreviation & Solubility \\
\hline 1: $\left[\mathrm{P}_{66614}{ }^{+}\right]\left[\mathrm{Ni}\left(\mathrm{T}_{\mathrm{h}} \mathrm{tfacac}\right)_{3}{ }^{-}\right.$ & $\mathrm{S}^{\mathrm{a}}, \mathrm{S}^{\mathrm{b}}, \mathrm{S}^{\mathrm{d}}, \mathrm{I}^{\mathrm{f}}$ & 13: $\left[\mathrm{C}_{14} \mathrm{MIM}^{+}\right]\left[\mathrm{Ni}\left(\mathrm{T}_{\mathrm{h}} \mathrm{tfacac}_{3_{3}}{ }^{-}\right]\right.$ & $\mathrm{S}^{\mathrm{a}}, \mathrm{S}^{\mathrm{b}}, \mathrm{I}^{\mathrm{e}}, \mathrm{I}^{\mathrm{f}}$ \\
\hline 2: $\left[\mathrm{P}_{66614}{ }^{+}\right]\left[\mathrm{Co}\left(\mathrm{T}_{\mathrm{h}} \mathrm{tfacac}_{3}\right)^{-}\right]$ & $\mathrm{S}^{\mathrm{a}}, \mathrm{S}^{\mathrm{b}}, \mathrm{S}^{\mathrm{d}}, \mathrm{I}^{\mathrm{f}}$ & 14: $\left[\mathrm{C}_{14} \mathrm{MIM}^{+}\right]\left[\mathrm{Co}\left(\mathrm{T}_{\mathrm{h}} \mathrm{tfacac}_{3}\right)^{-}\right]$ & $\mathrm{S}^{\mathrm{a}}, \mathrm{S}^{\mathrm{b}}, \mathrm{I}^{\mathrm{e}}, \mathrm{I}^{\mathrm{f}}$ \\
\hline 3: $\left[\mathrm{P}_{66614}{ }^{+}\right]\left[\mathrm{Mn}\left(\mathrm{T}_{\mathrm{h}} \mathrm{tfacac}_{3}{ }^{-}\right]\right.$ & $\mathrm{S}^{\mathrm{a}}, \mathrm{S}^{\mathrm{b}}, \mathrm{S}^{\mathrm{d}}, \mathrm{I}^{\mathrm{f}}$ & 15: $\left[\mathrm{C}_{14} \mathrm{MIM}^{+}\right]\left[\mathrm{Mn}\left(\mathrm{T}_{\mathrm{h}} \mathrm{tfacac}_{3}{ }^{-}\right]\right.$ & $\mathrm{S}^{\mathrm{a}}, \mathrm{S}^{\mathrm{b}}$ \\
\hline 5: $\left[\mathrm{P}_{66614}{ }^{+}\right]\left[\mathrm{Co}\left(\mathrm{N}_{\mathrm{p}} \mathrm{tfacac}_{3}{ }^{-}\right]\right.$ & $\mathrm{S}^{\mathrm{a}}, \mathrm{S}^{\mathrm{b}}, \mathrm{S}^{\mathrm{d}}, \mathrm{I}^{\mathrm{f}}$ & 17: $\left[\mathrm{C}_{14} \mathrm{MIM}^{+}\right]\left[\mathrm{Co}\left(\mathrm{N}_{\mathrm{p}} \mathrm{tfacac}_{3}{ }^{-}\right]\right.$ & $S^{\mathrm{a}}, \mathrm{S}^{\mathrm{b}}, \mathrm{I}^{\mathrm{e}}, \mathrm{I}^{\mathrm{f}}$ \\
\hline 6: $\left[\mathrm{P}_{66614}{ }^{+}\right]\left[\mathrm{Mn}\left(\mathrm{N}_{\mathrm{p}} \mathrm{tfacac}\right)_{3}{ }^{-}\right]$ & $S^{\mathrm{a}}, \mathrm{S}^{\mathrm{b}}, \mathrm{S}^{\mathrm{d}}, \mathrm{I}^{\mathrm{f}}$ & 18: $\left[\mathrm{C}_{14} \mathrm{MIM}^{+}\right]\left[\mathrm{Mn}\left(\mathrm{N}_{\mathrm{p}} \text { tfacac }\right)_{3}{ }^{-}\right]$ & $\mathrm{S}^{\mathrm{a}}, \mathrm{S}^{\mathrm{b}}, \mathrm{S}^{\mathrm{d}}, \mathrm{I}^{\mathrm{f}}$ \\
\hline 7: $\left[\mathrm{P}_{66614}{ }^{+}\right]\left[\mathrm{Ni}\left(\mathrm{P}_{\mathrm{h}} \mathrm{tfacac}\right)_{3}{ }^{-}\right]$ & $S^{\mathrm{a}}, \mathrm{S}^{\mathrm{b}}, \mathrm{S}^{\mathrm{c}}, \mathrm{I}_{\mathrm{f}}^{\mathrm{f}}$ & 19: $\left[\mathrm{C}_{14} \mathrm{MIM}^{+}\right]\left[\mathrm{Ni}\left(\mathrm{P}_{\mathrm{h}} \mathrm{tfacac}_{3}{ }^{-}\right]\right.$ & $S^{\mathrm{a}}, \mathrm{S}^{\mathrm{b}}, \mathrm{S}^{\mathrm{d}}, \mathrm{I}^{\mathrm{f}}$ \\
\hline 10: $\left[\mathrm{P}_{66614}\right]\left[\mathrm{Ni}(\text { tfacac })_{3}{ }^{-}\right]$ & $\mathrm{S}^{\mathrm{a}}, \mathrm{S}^{\mathrm{b}}, \mathrm{S}^{\mathrm{c}}, \mathrm{I}^{\mathrm{f}}$ & 22: $\left[\mathrm{C}_{14} \mathrm{MIM}^{+}\right]\left[\mathrm{Ni}(\text { tfacac })_{3}{ }^{-}\right]$ & $\mathrm{S}^{\mathrm{a}}, \mathrm{S}^{\mathrm{b}}$ \\
\hline 11: $\left[\mathrm{P}_{66614}{ }^{+}\right]\left[\mathrm{Co}(\mathrm{tfacac})_{3}{ }^{-}\right]$ & $\mathrm{S}^{\mathrm{a}}, \mathrm{S}^{\mathrm{b}}, \mathrm{S}^{\mathrm{c}}, \mathrm{I}^{\mathrm{f}}$ & 23: $\left[\mathrm{C}_{14} \mathrm{MIM}^{+}\right]\left[\mathrm{Co}\left(\mathrm{tfacac}_{3}{ }^{-}\right]\right.$ & \\
\hline 12: $\left[\mathrm{P}_{66614}{ }^{+}\right]\left[\mathrm{Mn}(\mathrm{tfacac})_{3}^{-}\right]$ & $\mathrm{S}^{\mathrm{a}}, \mathrm{S}^{\mathrm{b}}, \mathrm{S}^{\mathrm{c}}, \mathrm{I}^{\mathrm{f}}$ & 24: $\left[\mathrm{C}_{14} \mathrm{MIM}^{+}\right]\left[\mathrm{Mn}(\text { tfacac })_{3}{ }^{-}\right]$ & $\mathrm{S}^{\mathrm{a}}, \mathrm{S}^{\mathrm{b}}, \mathrm{s}$ \\
\hline
\end{tabular}

$\mathrm{S}^{\mathrm{a}}=$ soluble in diethyl ether, dichloromethane, chloroform, methanol, acetone and acetonitrile at $20 \%(\mathrm{w} / \mathrm{v}) . \mathrm{S}^{\mathrm{b}}=$ soluble in toluene and dimethyl sulfoxide at $10 \%(\mathrm{w} / \mathrm{v}) . \mathrm{S}^{\mathrm{c}}=$ soluble in hexane at $10 \%(\mathrm{w} / \mathrm{v}) . \mathrm{S}^{\mathrm{d}}=$ soluble in hexane at $<1 \%(\mathrm{w} / \mathrm{v}) . \mathrm{I}^{\mathrm{e}}=$ insoluble in hexane at $0.01 \%(\mathrm{w} / \mathrm{v})$. $\mathrm{I}^{\mathrm{f}}=$ insoluble in water at $0.01 \%(\mathrm{w} / \mathrm{v})$. 
in the viscosities for MILs comprised of imidazolium and phosphonium cations.

\subsection{Solvent miscibility}

The solubility of MILs in various organic solvents is very important in order to exploit them in applications including photoluminescent materials, ${ }^{43}$ liquid membranes, ${ }^{27}$ reaction media in organic synthesis, ${ }^{14,15}$ and catalysis. ${ }^{10,11}$ The solubility of MILs in ten different organic solvents, with polarities ranging from 0.009 to 1.000 according to the Reichardt polarity index, ${ }^{44}$ were studied to develop a fundamental understanding of their solubilities. A summary of the results is shown in Table 3. Since the MILs were designed to be hydrophobic and hydrolytically stable, all MILs were found to be insoluble in water at a $0.01 \%(\mathrm{w} / \mathrm{v})$ MIL-to-solvent ratio. The MILs were found to be fully miscible at $20 \%(\mathrm{w} / \mathrm{v})$ MIL-to-solvent ratio in most organic solvents including diethyl ether, dichloromethane, chloroform, methanol, acetone, and acetonitrile. Their solubility was found to be $10 \%(\mathrm{w} / \mathrm{v})$ in DMSO and toluene, which have polarity values of 0.444 and 0.099 , respectively. ${ }^{44}$ The MILs exhibited varying solubilities in hexane, with MILs 7-12 (containing $\mathrm{P}_{\mathrm{h}}$ tfacac and tfacac ligands and paired with the $\left[\mathrm{P}_{66614}{ }^{+}\right]$cation) possessing a solubility of $10 \%(\mathrm{w} / \mathrm{v})$. However, MILs 13-18 (containing $\mathrm{T}_{\mathrm{h}}$ tfacac and $\mathrm{N}_{\mathrm{p}}$ tfacac ligands and paired with $\left[\mathrm{C}_{14} \mathrm{MIM}^{+}\right]$cation) were found to be insoluble. The remaining MILs were only sparingly soluble in hexane, with a solubility of $<1 \%(w / v)$. The varying solubility of this generation of MILs in different organic solvents further enhances their versatility and range of applications in which they may find utility.

\section{Conclusions}

In this study, twenty four (24) different MILs with varying transition metal centers (Ni(II), Co(II), and Mn(II)), ligands ( $\mathrm{T}_{\mathrm{h}}$ tfacac, $\mathrm{N}_{\mathrm{p}} \mathrm{tfacac}$, $\mathrm{P}_{\mathrm{h}}$ tfacac, and tfacac) and cations $\left(\left[\mathrm{P}_{66614}{ }^{+}\right]\right.$or $\left.\left[\mathrm{C}_{14} \mathrm{MIM}^{+}\right]\right)$have been successfully synthesized and characterized. This study demonstrates that thermal stability of acetylacetone-based MILs can be increased through the incorporation of aromatic moieties in the ligand structure, as observed with MILs synthesized with thiophenyl, naphthyl, and phenyl-based ligands. Lower thermal stability was observed for MILs containing the tfacac ligand which lacks aromatic moieties within the ligand. The highest thermal stability was found to be approximately $260{ }^{\circ} \mathrm{C}$ for MIL $1\left(\left[\mathrm{P}_{66614}{ }^{+}\right]\left[\mathrm{Ni}(\mathrm{II})\left(\mathrm{T}_{\mathrm{h}} \text { tfacac }\right)_{3}{ }^{-}\right]\right)$, which is approximately $50{ }^{\circ} \mathrm{C}$ higher than previously reported acetylacetone-based MILs. Furthermore, viscosities ranging from a couple of hundred centipoise to several thousand centipoise were achieved. The lowest viscosities were achieved by incorporating the $\left[\mathrm{P}_{66614}{ }^{+}\right]$cation into the MIL structure. Conversely, MILs containing the imidazolium cation had much higher viscosities on average, with some MILs possessing melting points above room temperature. Magnetic susceptibility was found be in agreement with high spin complexes of transition metals (Ni(II), $\mathrm{Co}(\mathrm{II})$, and $\mathrm{Mn}$ (II)). The synthesized MILs were found to be extremely hydrophobic as they were insoluble in water down to a MIL-to-solvent ratio of $0.01 \%(\mathrm{w} / \mathrm{v})$. This study provides insight into the physiochemical properties of MILs and how they can be controlled through modification to various structural components including metal center, ligand, and cation.

\section{Conflicts of interest}

There are no conflicts to declare.

\section{Acknowledgements}

The authors acknowledge funding from Chemical Measurement and Imaging Program at the National Science Foundation (Grant number CHE-1709372). The Ames Laboratory is operated for the U.S. Department of Energy (DOE) by Iowa State University of Science and Technology under contract No. DE-AC02-07CH11358. Magnetic measurements (Y. M.) were supported by the Office of Science of the U.S. DOE, Division of Materials Sciences and Engineering, Office of Basic Energy Sciences. The authors acknowledge He Nan and Ester Peris García for their assistance in this study.

\section{References}

1 K. R. Seddon, J. Chem. Technol. Biotechnol., 1997, 68, 351-356.

2 J. P. Hallett and T. Welton, Chem. Rev., 2011, 111, 3508-3576.

3 A. J. Carmichael and K. R. Seddon, J. Phys. Org. Chem., 2000, 13, 591-595.

4 K. D. Clark, O. Nacham, J. A. Purslow, S. A. Pierson and J. L. Anderson, Anal. Chim. Acta, 2016, 934, 9-21.

5 S. Hayashi and H. Hamaguchi, Chem. Lett., 2004, 33, 1590-1591.

6 Y. Yoshida and G. Saito, Phys. Chem. Chem. Phys., 2010, 12, 1675-1684.

7 T. Inagaki and T. Mochida, Chem. Lett., 2010, 39, 572-573.

8 D. Chand, M. Q. Farooq, A. K. Pathak, J. Li, E. A. Smith and J. L. Anderson, New J. Chem., 2019, 43, 20-23.

9 D. K. Bwambok, M. M. Thuo, M. B. J. Atkinson, K. A. Mirica, N. D. Shapiro and G. M. Whitesides, Anal. Chem., 2013, 85, 8442-8447.

10 K. Bica and P. Gaertner, Eur. J. Org. Chem., 2008, 3453-3456.

11 M. Valkenberg, C. deCastro and W. Hölderich, Appl. Catal., A, 2001, 215, 185-190.

12 S. Hayashi, S. Saha and H. Hamaguchi, IEEE Trans. Magn., 2006, 42, 12-14.

13 J. Muraoka, N. Kamiya and Y. Ito, J. Mol. Liq., 2013, 182, 76-78.

14 Y. Tang, X. Hu, P. Guan, X. Lin and X. Li, J. Phys. Org. Chem., 2014, 27, 498-503.

15 M. E. Zakrzewska, A. B. Paninho, M. F. Môlho, A. V. M. Nunes, C. A. M. Afonso, A. A. Rosatella, J. M. Lopes and V. Najdanovic-Visak, J. Chem. Thermodyn., 2013, 63, 123-127.

16 A. Branco, L. C. Branco and F. Pina, Chem. Commun., 2011, 47, 2300-2302.

17 N. Deng, M. Li, L. Zhao, C. Lu, S. L. de Rooy and I. M. Warner, J. Hazard. Mater., 2011, 192, 1350-1357.

18 N. H. Ko, J. S. Lee, E. S. Huh, H. Lee, K. D. Jung, H. S. Kim and M. Cheong, Energy Fuels, 2008, 22, 1687-1690. 
19 J. Wang, H. Yao, Y. Nie, L. Bai, X. Zhang and J. Li, Ind. Eng. Chem. Res., 2012, 51, 3776-3782.

20 S. Zhang, Y. Zhang, Y. Wang, S. Liu and Y. Deng, Phys. Chem. Chem. Phys., 2012, 14, 5132-5138.

21 P. Brown, C. P. Butts, J. Eastoe, E. Padrón Hernández, F. L. de, A. Machado and R. J. de Oliveira, Chem. Commun., 2013, 49, 2765-2767.

22 O. Nacham, K. D. Clark, H. Yu and J. L. Anderson, Chem. Mater., 2015, 27, 923-931.

23 H. Nan, L. Peterson and J. L. Anderson, Anal. Bioanal. Chem., 2018, 410, 4597-4606.

24 C. Zhang, I. C. Ingram, L. W. Hantao and J. L. Anderson, J. Chromatogr. A, 2015, 1386, 89-97.

25 M. M. Cruz, R. P. Borges, M. Godinho, C. S. Marques, E. Langa, A. P. C. Ribeiro, M. J. V. Lourenço, F. J. V. Santos, C. A. Nieto de Castro, M. Macatrão, M. Tariq, J. M. S. S. Esperança, J. N. Canongia Lopes, C. A. M. Afonso and L. P. N. Rebelo, Fluid Phase Equilib., 2013, 350, 43-50.

26 R. E. Del Sesto, C. Corley, A. Robertson and J. S. Wilkes, J. Organomet. Chem., 2005, 690, 2536-2542.

27 E. Santos, J. Albo, A. Rosatella, C. A. M. Afonso and Á. Irabien, J. Chem. Technol. Biotechnol., 2014, 89, 866-871.

28 Y. Yoshida and G. Saito, J. Mater. Chem., 2006, 16, 1254-1262.

29 J. An, K. L. Rahn and J. L. Anderson, Talanta, 2017, 167, 268-278.

30 S. A. Pierson, O. Nacham, K. D. Clark, H. Nan, Y. Mudryk and J. L. Anderson, New J. Chem., 2017, 41, 5498-5505.
31 R. E. Del Sesto, T. M. McCleskey, A. K. Burrell, G. A. Baker, J. D. Thompson, B. L. Scott, J. S. Wilkes and P. Williams, Chem. Commun., 2008, 447-449.

32 H. Mehdi, K. Binnemans, K. Van Hecke, L. Van Meervelt and P. Nockemann, Chem. Commun., 2010, 46, 234-236.

33 T. Payagala, Y. Zhang, E. Wanigasekara, K. Huang, Z. S. Breitbach, P. S. Sharma, L. M. Sidisky and D. W. Armstrong, Anal. Chem., 2009, 81, 160-173.

34 P. Zhang, Y. Gong, Y. Lv, Y. Guo, Y. Wang, C. Wang and H. Li, Chem. Commun., 2012, 48, 2334-2336.

35 K. Nakamoto, C. Udovich and J. Takemoto, J. Am. Chem. Soc., 1970, 92, 3973-3976.

36 H. Yu, J. Merib and J. L. Anderson, J. Chromatogr. A, 2016, 1463, 11-19.

37 R. A. Patil, M. Talebi, A. Berthod and D. W. Armstrong, Anal. Bioanal. Chem., 2018, 410, 4645-4655.

38 N. Raman, S. Ravichandran and C. Thangaraja, J. Chem. Sci., 2004, 116, 215-219.

39 F. H. Field and W. C. Vosburgh, J. Am. Chem. Soc., 1949, 71, 2398-2401.

40 E. Koubek and M. Elert, J. Chem. Educ., 1996, 73, 947.

41 R. van Gorkum, F. Buda, H. Kooijman, A. L. Spek, E. Bouwman and J. Reedijk, Eur. J. Inorg. Chem., 2005, 2255-2261.

42 N. C. Pernicone, J. B. Geri and J. T. York, J. Chem. Educ., 2011, 88, 1323-1327.

43 A. Babai and A. V. Mudring, Chem. Mater., 2005, 17, 6230-6238. 44 C. Reichardt, Chem. Rev., 1994, 94, 2319-2358. 